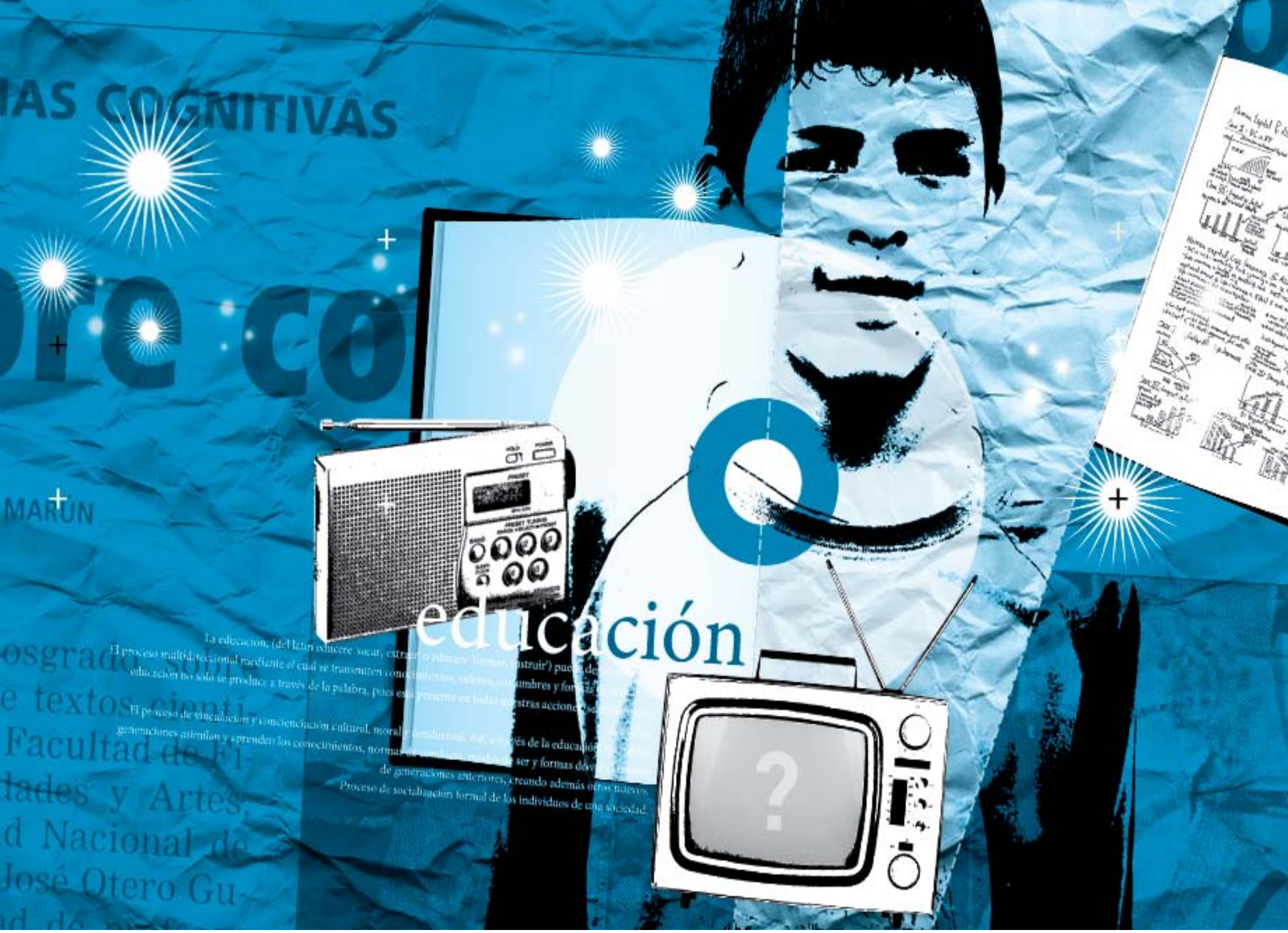

\title{
El horizonte humano: un saber necesario en tiempos de crisis*
}

Este artículo de reflexión es producto de un proceso de intervención e investigación realizado en 6 jardines sociales en el sector rural en el departamento de Boyacá, con la participación de los investigadores Hernán Javier Riveros Solórzano e Ingrid Rocío Sánchez Paredes, en aras de identificar elementos necesarios para el trabajo en Derechos Humanos y Escuelas de Padres en primera infancia.
HERNÁN JAVIER
Riveros Solórzano
INGRID Rocío
SÁnchez Paredes 
El horizonte humano: un saber necesario en tiempos de crisis

Resumen:
Junto a los avances tecnológicos de la
postmodernidad también se han gesta-
do, con el consumo, el individualismo y
la desigualdad, una serie de violencias
y fracturas en la condición humana
que exigen de propuestas educativas
capaces de apuntar al desarrollo del
ser. Un desafío que demanda al aula
abrir sus fronteras a la humanización
desde los niveles iniciales. Este artículo
presenta una propuesta de construc-
ción de saberes a escala de “especie
humana”, producto de las reflexiones
emanadas de seis experiencias de aula
en formación en Derechos Humanos en
primera infancia.
Palabras clave: humanización,
complejidad, postmodernidad,
primera infancia, Derechos
Humanos.

Knowledge and skills in education. A ratreo by UNESCO reports of Jacques Delors and Edgar Morin

Summary:
With the technological progress of the
post- modernity, a series of violence
and fractures in the human condi-
tion have appeared, along with the
consumption, the individualism and
the inequality that require an edu-
cational proposal able to aim at the
development of the human being as a
being. A challenge that requests from
the classroom, to open its borders to
humanization from the essential values.
This article brings in a proposal of
human scale knowledge construction,
result of the reflections emerged from
six classroom experiences in training in
early childhood human rights.
Keywords: humanization, complexity,
post modernity, early childhood,
Human Rights.

0 horizonte humano: um saber necesario em tempos de crise

\section{Hernán Javier Riveros Solórzano}

Candidato a Mg. en Comunicación - Educación de la Universidad Distrital Francisco José de

Caldas; Especialista en Pedagogía de la Comunicación y Medios Interactivos de la Universidad

Distrital Francisco José de Caldas y Lic. en Lingüística y Literatura de la Universidad Distrital

Francisco José de Caldas. Docente Tutor de la Universidad Francisco de Paula Santander CREAD,

Bogotá y Docente en la Universida Distrital Francisco José de Caldas. hriveros95@gmail.com

\section{Ingrid Rocío Sánchez Paredes}

Especialista en Pedagogía de los Derechos Humanos de la Universidad Pedagógica y Tecnológica de Colombia (U.P.T.C.); Psicóloga social comunitaria de la UNAD. Tallerista y orientadora en el campo de primera infancia en COMFABOY y el I.CB.F. ingridangel1983@hotmail.com.ar 


\footnotetext{
"Mientras que la especie humana continúa su aventura bajo la amenaza de la autodestrucción, el imperativo es: salvar a la humanidad realizándola”.
}

Las transformaciones de los tiempos actuales apuntan innegablemente a una paradoja entre crisis y desarrollo. Junto a los grandes avances dados a partir de la consolidación de las incertidumbres y la deslegitimación de los relatos orientadores (Lyotard, 1986), los abismos en el campo de la condición humana empezaron a hacerse más profundos e insondables. En este tiempo, en paralelo a los impulsos de la tecnología y la aparición de sociedades red (Castells, 2010), también los caminos de nuevas violencias hard (Lipovetsky, 2006), indiferencias, desterritorializaciones y fracturas en el concepto de cohesión social (Bauman, 2009), comenzaron a tomarse el panorama de la postmodernidad.

Desafíos innegables hacen presencia en tiempos de cambio de paradigmas, de búsquedas en lo inexplorado y descubrimientos notables, pero también de distancias agudas, individualismos exacerbados y crueldades inexplicables en las que los saberes enfrentan un desafío innegable en sus configuraciones, pues mientras la digitalización acercó al ser humano cada vez más a conocimientos jamás imaginados, en un nuevo espíritu científico crítico y en construcción permanente, las distancias con el "otro" y la amenaza de la autodestrucción (Morin, 1999), empezaron a gestarse como lo rostros paradójicos del progreso de la era del vacío (Lipovetsky, 2006). Un desafío que invita a preguntarse desde la arena pedagógica frente a ¿cómo responder a estos retos desde la escuela?, ¿qué camino tomar en tiempos de desarrollo científico y abismos humanos?, ¿qué nuevos senderos trazar desde el aula?
Retomar la senda de lo humano y restaurar los lazos comunicativos como puente del entendimiento de la otredad, así como también la reivindicación de la inocencia y de la posibilidad del ejercicio de la comprensión de sí, de los demás y esencialmente de la noción de "especie humana” (Morin, 1999), son las vías para caminar en pos de la humanización necesaria para tiempos de avance tecnológico y violencias crecientes. La escuela, por tanto, desde los primeros pasos tiene en sus manos la responsabilidad de abrir las puertas a los niños y niñas hacia la construcción de lazos sociales y de tejidos humanos que respondan a las paradojas de nuestro tiempo, y consoliden puntos de encuentro entre el avance de los saberes científicos y la creación de comunidades incluyentes y polifónicas.

A partir de esta idea y de las reflexiones suscitadas por seis experiencias de aula ${ }^{1}$ desarrolladas con Primera Infancia desde el campo de los Derechos Humanos, surge como propuesta el planteamiento de realizar una apuesta por la humanización desde la comprensión del ser en su mismidad, en su relación con otros, y desde los ámbitos de la familia y la escuela. Un camino en el que el aula se convierte en el escenario para desarrollar saberes, no solamente como la integración de las diversas dimensiones del conocimiento científico, sino también

1 Las experiencias se desarrollaron durante el año 2012 en seis instituciones educativas ubicadas en el Departamento de Boyacá: Jardín Social Nobsanitos, Jardín Social Raquel Puentes de Palacios Jardín Social Morada del Sol, Jardín Social Travesuras, Institución Educativa Juan José Reyes Patria e Institución Educativa Nuestra Señora de Morcá 


\section{En este panorama de crisis, atomización de los valores e indiferencia, el escenario escolar enfrenta una serie de adaptaciones y proliferación de violencias y persecuciones. 99}

desde la consolidación de una ética del género humano (Morin, 1999), en la que la comprensión es la alternativa ante el hiperindividualismo (Lipovetsky, 2006). Sin embargo, antes de entrar en la propuesta, es necesario conocer las problemáticas que presentan los actuales tiempos de paradojas, transformaciones y crisis.

\section{Tiempos de crisis, consumo y violencias}

La postmodernidad, hipermodernidad, modernidad eclipsada, otra modernidad o modernidad líquida ${ }^{2}$, ha sido testigo del avance dinámico de los flujos y la velocidad del desarrollo científico-técnico y digital, pero también del crecimiento de una pérdida de la cohesión social a causa del aumento del individualismo y la vida de consumo. Con una interiorización de la competencia y el hedonismo, aparecen en el horizonte nuevas violencias que desbordan incluso los ámbitos de la política (que caracterizaron los grandes conflictos de la Modernidad), y que van desde el sin sentido hasta las problemáticas al interior de las familias y los fenómenos de acoso, segregación y discriminación. La humanidad en este contexto, aunque camina con decisión hacia el desarrollo de nuevas construcciones tecnológicas, se desmorona en una especie de autodestrucción ${ }^{3}$ y vacío.

2 Los fenómenos culturales y sociales de finales de siglo XX y comienzos del XXI, se han analizado desde diversas perspectivas teóricas que han dado diferentes denominaciones a los tiempos en cuestión, y entre los que se tejen elementos comunes, tales como la deslegitimación y la mutación de los valores e ideales Modernos, haciendo incluso una "modernización de la modernidad".

3 Morin (1999), sostiene con vehemencia dentro de sus propuestas de saberes necesarios para la educación del futuro, volver los ojos sobre la forma en que se está produciendo un camino hacia la autodestrucción. Algo que también afirma, en compañía de Baudrillard (2004), en el marco de la consolidación en tiempos de consumo e individualización de una enorme violencia en el mundo.
Esto se explica toda vez que en paralelo a cuestiones como la deslegitimación (Lyotard, 1986) y la pérdida de la densidad en los discursos (Bauman, 2010), el consumo y el mercado se convirtieron en paradigmas de innegable valor, tanto desde el punto de vista del intercambio simbólico (Baudrillard, 2009), como en la configuración de una serie de hedonismos, narcisismos e individualismos (Lipovetsky, 2006), propios de una sociedad basada en la competitividad de una racionalidad encumbrada en la posesión y rápido desecho de los objetos (Bauman, 2010), pero también en la pertenencia a toda costa en el star system (Lipovetsky, 2006); todos ellos implican dos premisas en las que lo humano deja de ser un fin: la configuración del ser como cosa (Bauman, 2005), y la dinámica de la negación del otro. En el mundo del Narciso que consume, los demás son sus enemigos y el éxito personal se eleva por encima de la necesidad de cohesión social propia de un humanismo sin compromisos.

Desintegrados, solitarios y en competencia permanente, aparecen en el panorama de las sociedades postmodernas el surgimiento de las violencias sin sentido que ya no se libran en las arenas políticas, sino en los hogares, las calles e incluso las plataformas virtuales, en donde el problema ya no sólo pertenece al ámbito de las desigualdades, sino incluso a la necesidad de triunfo, de demostración de poder y a la indiferencia propia de un desencanto postmoderno (Fajardo, 2005) en el que no solamente los grandes relatos orientadores se han resquebrajado, sino también el estremecimiento ante el dolor de los otros y la conciencia de la pertenencia a la especie humana.

Se trata entonces de una cadena de violencias que inicia desde la competencia y su combinación con la indiferencia y el irrespeto al otro. Una problemática de múltiples rostros que golpea en las puertas de los hogares e incluso se hace cotidiana y adquiere diversas formas, desde las palabras que laceran la mente, hasta los golpes y sus secuelas permanentes, y que ha llegado a la configuración de nuevas sensibilidades ante el sufrimiento, que hayan su triunfo en la consolidación de la existencia de la muerte como espectáculo (Marzano, 2010).

$\mathrm{El}$ asesinato, el crimen, la venganza y las armas, se toman las pantallas y generan los héroes y las sintonías de la cultura de la Modernidad líquida. Son el espacio 


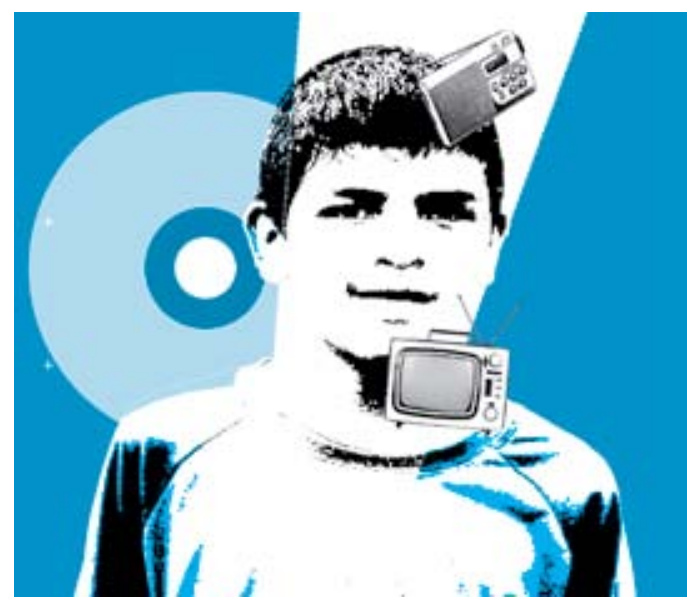

para la relajación de Narciso y la enajenación ante el sufrimiento $^{4}$, un carnaval oscuro que sirve para distanciarse del otro y divinizar éticas de la crueldad y la revancha. Un espacio en el que las violencias múltiples se masifican y, junto con la idea de una sociedad psi, light y terapéutica ${ }^{5}$, resquebrajan el valor de lo humano dejándolo no solamente como un objeto de consumo, sino como un elemento prescindible y desdeñable en el momento del triunfo. El narcisismo postmoderno triunfa cuando en la pantalla no se vence al estrechar al otro, sino al pararse sobre él.

4 Fajardo (2010) plantea la forma en que en tiempos como los actuales el relajamiento se une dinámicamente con el individualismo para producir distanciamiento ante el dolor de los otros. Marzano (2010), también señala esta misma problemática como consecuencia de la forma en que en las pantallas se ha vuelto habitual la violencia y la muerte.

5 Lipovetsky (2006), afirma con claridad la manera en que las perspectivas de la sociedad contemporánea, regida por elementos propios del consumo y la moda, devienen en la consolidación de una cultura psi que se psicologiza o, en otras palabras, comienza a consolidar un culto obsesivo con la idea del bienestar, no como un ideal complejo, sino como concordancia con los dictámenes de una cultura light, que deviene, como señala Fajardo (2005), en la conformación de una sociedad terapéutica, que escapa a la otredad y se refugia en el individualismo y en lo efímero.
En este panorama de crisis, atomización de los valores e indiferencia, el escenario escolar enfrenta una serie de adaptaciones y proliferación de violencias y persecuciones. Surge así el bullying, pero también las huellas del maltrato en casa y la incomunicación de una sociedad que se informa pero que ha olvidado el acercamiento. Niños y niñas que se refugian en las esquinas, que aparecen con moretones, que sufren acoso en las sociedades red y que llegan a fenómenos preocupantes como el suicidio, evidencian una problemática propia de una crisis humana en medio del amplio desarrollo de la ciencia, en donde paradójicamente se pueden almacenar millones de datos en la palma de una mano, pero al tiempo se ve en televisión el suicidio de una niña ante sus compañeritos. Las violencias no sólo se esparcen por las pantallas y se viven en lo íntimo, sino que también caminan en la escuela.

Ahí está la problemática y el abismo, el reto que implica la interiorización de la violencia y sus múltiples manifestaciones, ante el que la educación tiene el deber de ofrecer un camino, una vía para propiciar la libertad y el respeto, la comprensión y el entendimiento. Una acción que debe llevarse a cabo en todos los momentos de desarrollo, incluso desde cuando se abandona la cuna y el aula se convierte en un segundo hogar. El reto está entonces ya no solamente en la construcción de los saberes que respondan a las incertidumbres y que integren las diversas dimensiones del ser y la totalidad con la particularidad, sino en darle cabida a una ética del género humano (Morin, 1999), que religue nuestra identidad como especie y como constructora del tejido que sostiene nuestros avances y donde el ser es el fin último y no un medio. ¿Cómo empezar a caminar ante este desafío?

\section{Formar desde la primera infancia}

El primer punto a tener en cuenta es que para formar desde la condición humana es necesaria la comprensión de que el concepto de seres humanos va mucho más allá de las condiciones físicas, psíquicas, biológicas y sociales. Se trata del entendimiento de que la Humanidad se liga dinámicamente con el conjunto de seres que le componen, con su complejidad individual, sus nexos y tejidos sociales, el denominado "bucle individuo-especie" (Morin, 1999), y las relaciones que se establecen con el 


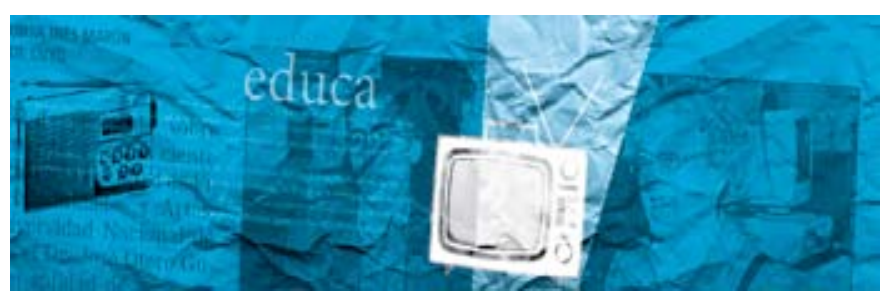

ambiente, la cultura y la historia. Por tanto, la tarea consiste en generar los espacios para acceder a estos saberes y que los mismos puedan orientarse, desde los primeros pasos que permitan poner los ladrillos, para construir un edificio humano e incluyente.

Es así como la Primera Infancia, entendida como un estadio de desarrollo en el que comienzan a formarse los sistemas de pensamiento (Vigotsky, 1967), se convierte en el escenario en el que se pueden comenzar a generar los espacios para la humanización. Las primeras edades, con sus necesidades, particularidades e inocencias, se ofrecen como el primer lugar para la configuración de una identidad tanto personal como planetaria (Morin, 1999); todo, desde procesos tan necesarios como el autoreconocimiento y el entendimiento y valoración de las diferencias.

Se trata de comenzar a generar espacios y dinámicas que desde el universo concreto que corresponde al nivel de desarrollo, lleven a la comprensión de sí y de quienes le rodean. Crecer y ser, jugar y aprender, compartir y descubrirse a sí mismo, esos fueron los nortes que se plantearon desde una propuesta multifocal de desarrollo, que implica a los estudiantes pero también a sus familias y a los docentes, que reconoce el ejercicio educativo como un proceso complejo, diverso, y que en el campo humano no puede olvidar el principio básico para la humanización de la igualdad (Medina Gallego, 2007).

Equidad antes que exclusión, compartir antes que competir, amarse y amar antes que atacar y ser libre, y llegar a acuerdos antes que imponer y castigar (Castro Pinzón, 2000), fueron los ejes desde los cuales se consolidaron las ideas que orientaron las experiencias base de esta propuesta, en la que se apuntó a trabajar desde 3 puntos esenciales: el niño(a) en su relación consigo mismo y con otros, desde el entendimiento y el respeto de los Derechos Humanos esenciales; el desarrollo de un proceso de acción comunicativa (Habermas, 1987) en familia, y, por último, la consolidación de espacios de comprensión desde las aulas.

\section{El niño(a): autoestima, nutrición y entendimiento}

Antes de pensar en el respeto al otro, es necesario comenzar por el entendimiento de sí mismo. La comprensión del ser y sus dinámicas, y el cuidado de la salud física, mental y emocional, son el paso inicial para poder ofrecerse a los demás y empezar a hacer consciencia de la importancia de sus Derechos y de su condición humana. Por tanto, en el primer momento de las experiencias de esta propuesta, el primer punto a desarrollar fue justamente el universo del niño (a) y sus procesos de autoestima y nutrición que, en el campo de la primera infancia, demandaban la presencia del juego y la interacción como mecanismos de exploración de mundo y de construcción del conocimiento base para poder estrechar al otro: el quererse a sí mismo.

Así, en la concepción de la propuesta, el juego y el relato, como motores de la modalidad narrativa de pensamiento (Bruner, 1980), fueron los puntos de partida en las seis experiencias. Se trataba de descubrir la propia imagen y consolidarla por encima de la psicologización postmoderna (Lipovetsky, 2006), como un sistema dinámico y un ecosistema personal, una red de tejidos y conexiones comunicativas maravillosamente conectadas, en las que el motor esencial no es otro que el creer en las propias potencialidades del ser en su complejidad (Morin, 1999).

Jugar a dibujarse, a representarse ante sí, a valorar cada espacio imaginado en la plastilina, con los cubos o con los dibujos, tener la libertad de correr e inventar sus propios juegos y recibir el aplauso por poder ser campeones en el "arrastre de sillas", fueron algunas de las actividades que compusieron este momento de las experiencias y que evidenciaban con contundencia que, tras la imagen de sí mismo, es posible consolidar la aceptación y el reconocimiento del valor y el esfuerzo propio, y que su fortalecimiento no está a mayor distancia de una sonrisa. 
Ahora bien, teniendo en cuenta la condición compleja y multidimensional del ser (Morin, 1999), el escenario del "yo" en desarrollo no podía dejar de lado aspectos tan importantes y preocupantes de la cultura postmoderna como aquel que se refiere a la nutrición. En oposición al imaginario light (Fajardo, 2005) y a la preocupante preponderancia del estar en forma ${ }^{6}$ (Bauman, 2010), comenzar a cimentar las bases de una alimentación sana implica comprender la manera en que el cuerpo funciona como una máquina de perfección magistral, y que desde la infancia se comprenda que en el respeto por sí mismo es importante comprender el papel de los alimentos y la forma en que funcionan como el combustible del cuerpo.

En el contexto del juego planteado para las experiencias, este fue el momento para expandir las fronteras de la escuela a la cocina. Preparar con plastilina, jugar con alimentos de felpa, hacer rondas en torno a los grupos alimenticios y lanzarse a ubicar imágenes en pirámides de nutrición, se eligieron como las dinámicas propicias y necesarias. Sin hablar teóricamente, sino con el amor y la concreción de su condición de encontrarse en el primer estadio de desarrollo (Piaget, 1975); en este momento la propuesta se convierte en el planteamiento de alternativas y de acercamientos a una conciencia sobre la forma en que entenderse a sí mismo equivale a alimentarse a conciencia.

Autodescubrirse, comprenderse, amarse y establecer los caminos para entender el cuerpo como templo, fueron los ejes del primer abordaje de las experiencias. Sin embargo, con el niño (a) puesto en el escenario de su autodescubrimiento, la cuestión siguiente es comenzar a entender, desde la práctica, la existencia de los Derechos Humanos y su vivencia plena en la relación con otros, fundamentada en el entendimiento, en la acción comunicativa (Habermas, 1987). Se trata de la interiorización a través de la lúdica del valor del otro, de su papel como complemento del yo (Paz, 1994), desde

6 Bauman (2010), plantea la manera en que dentro de la Modernidad Líquida se ha consolidado más allá del cuidado de la salud, la idea de "estar en forma" como parte de una entronización del consumo. De este modo, de acuerdo con este teórico, se puede incluso afectar el equilibrio corporal en aras de lograr estar acorde con la imagen impuesta por los valores cambiantes y líquidos de este tiempo. el respeto a su libertad, sus ideas y su carácter complementario; desde la diferencia en un marco de consolidación de una cultura cuyo principio es la valoración de los Derechos Humanos (Buenaventura, 1997). Así, en las experiencias, del juego con el "yo", se pasó a la exploración dinámica con el "nos".

Tocar al otro, sentirlo, ponerlo como un par real y no como una ilusión en la distancia (Sábato, 2010) fue el objetivo central de esta fase del proceso. La confianza, el equipo interiorizado como dinámica y la conformación de lazos de unión y fraternidad se convirtieron en los protagonistas de esta etapa. La idea esencial era plantear desde la planeación por escenarios y los juegos en grupo, las bases para entender desde los primeros pasos que solamente se logra hacer camino cuando se juntan las manos y no cuando se apartan aquellas que son distintas.

Las dinámicas que antes se hacían en soledad comenzaron a implicar a los pares, mientras que conceptos tan complejos como la confianza fueron puestos con toda seriedad en los juegos grupales, pues enseñar a convivir no es algo que pueda hacerse desde tableros y reflexiones (menos aún en niños y niñas tan pequeños), sino desde la interacción con el otro y su abordaje como complemento y parte de una humanidad que sólo resulta posible como un concepto emanado del compartir y de la integración del individuo con la especie (Morin, 1999). Jugar a confiar, a esperar y a escuchar se convirtió en el motor de la experiencia.

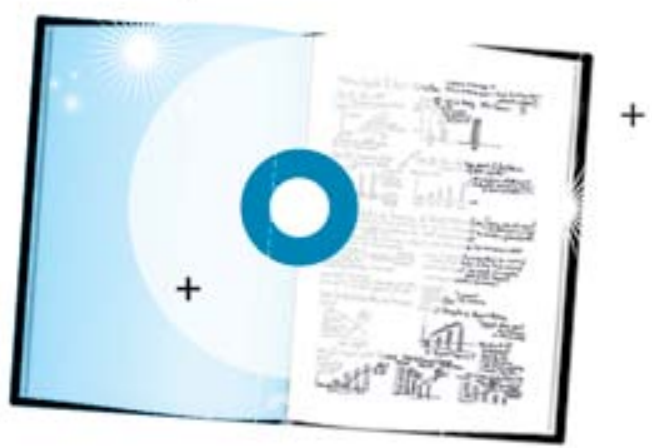


En este plano, ejercicios como construir muñecos y edificaciones con piezas de lego en equipo, armar rompecabezas juntos, pintar en grupo, armando pequeños cadáveres exquisitos con temperas y pinceles compartidos, y jugar a cenar en compañía, identificando por turnos y mediante canciones y rondas los alimentos y su valor, se hicieron parte de la dinámica de entender al otro. El ejercicio de comprensión de los Derechos Humanos resultaba de este modo como la consecuencia de que su práctica se hace valiosa cuando se integra con la vida, cuando no es solamente un acta, sino que en el mundo simulado de los juegos infantiles puede vivirse con la misma seriedad que exigen los conflictos más difíciles.

Para la dinámica de los Derechos Humanos, se propusieron juegos como "dilo como quieras", "¿en que no estamos de acuerdo?” y "nuestros espacios sagrados”, en los que asuntos como la libertad de expresión, la comunicación y el respeto a la libertad y el espacio del otro se convirtieran en hechos fundamentales desde la práctica y no en la teoría. El niño y la niña, capaz de escuchar a su par gritar a viva voz o de cantarlo con toda creatividad, que no le gustaban los lunes, que prefería el fútbol a jugar con muñecas, que no le gustaba que le tocaran sus juguetes y de respetar sus espacios en los juegos y demarcarlos, sin tener que recitar la Declaración de los Derechos Humanos, estaba aprendiendo a cumplirla, a vivirla con sus compañeros y a consolidar una comunidad humana.

Entender al otro, respetando sus Derechos desde la interacción, generar alternativas para dejarle ser y ser a su lado, constituyen la alternativa al egoísmo narcisista heredado del consumo y la competencia. El bullying, en este contexto, se convierte en un fenómeno que antes de contrarrestarse, se evita, cuando desde la cuna se enseña a entender al diferente, a respetar sus espacios y a promover sus libertades. El niño y la niña que aprenden a vibrar ante la presencia humana, serán aquellos que no se sentirán tentados al abuso, pues entienden que para poder ser, parafraseando a Octavio $\mathrm{Paz}$, se debe estar con los otros y sentirse completo sólo cuando se está en compañía de los demás.

Pero en los niños no se detienen los alcances del desafío de consolidar respeto por la especie. La familia, que en tiempos como los actuales presenta una diver-

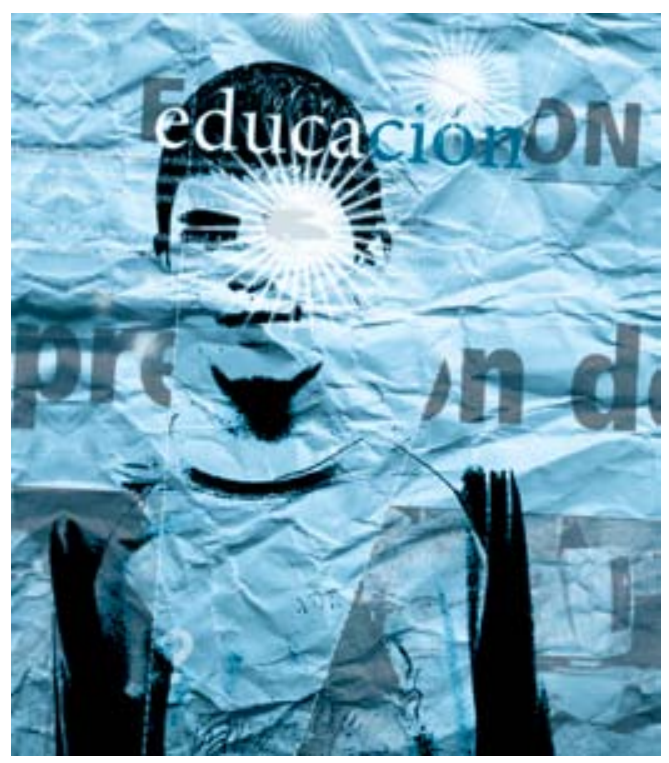

sidad absolutamente compleja y heterogénea, así como las secuelas y consecuencias de las violencias hard, transpolíticas $^{7}$ (Mendoza, 2012), y en ocasiones de los conflictos políticos con fenómenos como el desplazamiento y el carácter de víctimas de los grupos armados, debe ser otro de los puntos esenciales de trabajo en consolidación de una ética del género humano (Morin, 1999). Así, en esta experiencia, la escuela abre sus puertas a los padres, los hermanos, los abuelos y los acudientes, no a ser convidados de piedra o a participar en charlas, sino a involucrarse y a entender su función decisiva en el futuro de los ciudadanos del mañana.

\section{Comunicación en familia}

Abrir el espacio escolar a quienes viven con los niños supone comprender ante todo que la familia juega un papel vital en el desarrollo del niño (a). Las imágenes,

7 Así como Lipovetsky (2006) señala un tipo de violencia que designa como hard dada su naturaleza sin sentido, Mendoza (2012), plantea la existencia de una forma transpolítica, que se refiere a todo conflicto en el que no se interviene políticamente, sino que, como en el caso de la violencia intrafamiliar, afecta a la sociedad en conjunto en escenarios mucho más cotidianos. 
palabras, referencias, contenidos y experiencias que se generan en casa, marcan significativamente los imaginarios, concepciones e ideas que se forman sobre el mundo y sus escenarios. Por tanto, establecer puentes comunicativos y de coherencia con la formación que se genera desde casa, constituye un factor de necesaria significación en el entendimiento de lo humano, no como una categoría abstracta, sino como parte de la vivencia cotidiana.

En esta fase, del juego se pasó al taller y a la simulación. La fábula y el relato, así como la moraleja y la canción, se hicieron partícipes de la experiencia con padres y familiares que jugaban con sus hijos en el aula de clase, que se divertían con la inversión de roles, con la preparación de ensaladas de frutas en grupo y con la discusión en torno a las historias de mamá canguro y la familia $b \mathrm{hho}^{8}$. La idea era gestar en la familia, sin importar su clase o conformación, y con comprensión de su historia y dinámica propias, el concepto de refugio, de hogar y de espacio de encuentro comunicativo y de desarrollo intersubjetivo.

Pensar como unidad, encontrar apoyo al llegar a casa, fortalecer el sí mismo con palmadas en la espalda, superar las crisis con la sonrisa y la ternura del amor de los más pequeños y, ante las dificultades, crear alternativas desde el juego en familia, fueron los objetivos de este momento de las experiencias. Se trataba de interiorizar el hecho de que a pesar de las violencias, de sus secuelas y de los avatares de la vida, en una cultura humana el entorno familiar se consolida como un sistema comunicativo que ante el dolor opone la comprensión, en el cual el apoyo y la libertad se convierten en nociones que se viven cuando hay guía y escucha, cuando los niños y niñas se llevan de la mano para que sean capaces de construir sus alas y volar al infinito con buenos recuerdos en la memoria, cuando se considera que frente al dolor del mundo siempre habrá la mirada esperanzada de sus padres, sus hermanos y quienes vivieron en el hogar donde forjaron sus almas de pegaso.

8 Estas dos fabulas plantean dos ideas de familia, la de mamá canguro se refiere a la sobreprotección y la de la familia búho, al apoyo mutuo. Fueron usadas como marco de reflexión en las seis experiencias de aula y tomadas de Suárez Higuera (2003).
Formar en familia no es una tarea fácil, implica el cambio de imaginarios en los mayores, el establecimiento de la interiorización de la comunicación como encuentro intersubjetivo y como acción dinámica (Habermas, 1987). Se trata de cambiar y consolidar nuevos paradigmas, de llevar a consolidar que la crianza no es sinónimo del condicionamiento y que las imágenes que se forman en familia tienen alcances y duraciones que superan fácilmente el instante; todo, sin caer en el mundo de la terapia constante, construir humanización desde la familia implica llevar a que el hogar se semeje a un nido y los otros no sean vistos desde el individualismo de nuestros tiempos, sino desde la dinámica grupal en la que el bienestar del otro es la ganancia propia.

Sin embargo, en el desarrollo de las experiencias que orientan estas ideas, no solamente se identificó en la familia un motor de la tarea de la humanización. Los docentes, como parte del espacio de desarrollo escolar, se convirtieron en otro objetivo de trabajo, de interiorización de que los números son a veces menos importantes que un abrazo y que en sociedades donde las violencias avanzan con contundencia, las escuelas también pueden no sólo ser los templos de la academia, sino que pueden convertirse en los espacios donde el dolor se puede curar (Koplow, 2005).

\section{El papel vital de los docentes}

Ser docente es un compromiso, una responsabilidad y una vocación. El ejercicio pedagógico va mucho más allá de la enseñanza de contenidos, implica la conformación y consolidación de las sociedades futuras y el vínculo con el mañana y sus aciertos y errores. El profesor no solamente es quien espera a sus estudiantes con un almacén descomunal de contenidos, sino quien abre sus brazos a quienes apenas empiezan el camino de la vida para guiarles hacia el mañana y, en la barca del saber, les permite ver que no sólo de contenidos científicos está hecho el mundo, sino que los otros y la Humanidad son de lejos el conocimiento más importante que se puede formar.

Así, en tiempos de crisis, de soledades y de traumas que a veces se esconden en los silencios de los niños (as), el docente tiene la responsabilidad de hacer 
consciencia de su vocación de servicio y ayudar a sanar heridas, olvidar por un momento la exigencia de los libros y de la memoria, y saber que en sus manos puede estar incluso una vida o un mañana. Enseñar, de este modo, no puede ser otro asunto distinto que mediar, conversar, impulsar y entender que no se es mejor cuando se pierde, sino cuando se logra vencer las dificultades, y que momentos tan decisivos como la evaluación, tal como lo plantea Santos Guerra (2010), antes de ser tiempos para el temor y el miedo (ya bastante desarrollados con la señalada por Morin y Baudrillard $^{9}(2004)$, violencia del mundo), deben ser escenarios para crecer, ser y crear.

En el marco de las experiencias desarrolladas y a partir de estas premisas, se trabajó con los docentes hacia la interiorización de lo humano en sus clases, como al hacer las vocales, ejercicio que podía verse como un espacio para viajar hacia la Humanidad, y reconocer los números, que implicaba un ejercicio de entendimiento y negociación. En la arena de la discusión con profesores se gestaron, mediante la dinámica del taller, los escenarios para repensar la profesión y formular las propuestas y los compromisos con la humanización de las clases, lo que nunca implica dejar a un lado los contenidos, sino entender que ellos pasan por la esfera del ser y son sólo un aspecto de su infinita complejidad.

En estas discusiones, también apareció la noción necesaria e importante del docente investigador, reflexivo sobre su propia práctica. En los momentos de socialización con los profesores, se puso sobre la mesa la importancia de preguntarse, de hacer y de cambiar conforme las necesidades, no sólo de la academia, sino de lo humano. Hacer espacio a la felicitación, a estrechar la mano al compañero y a compartir onces, accione que pueden hacer más por una sociedad en crisis que una tanda completa de ejercicios o una seguidilla de tablas de multiplicar, sin restarle su importancia. El docente, tiene pues en sus manos, junto con la familia y los propios estudiantes, el camino abonado para pensarse como navegante en las incertidumbres postmodernas y

9 Morin y Baudrillard (2004) plantean la existencia de una violencia en el mundo en una escala preocupante y que se dirige por un lado a la autodestrucción y por otro a los ataques sin piedad ni sentido. con la responsabilidad de poner el faro para un desarrollo a escala humana. Esa es la responsabilidad y el desafío de las aulas en medio de los conflictos y las crisis.

\section{Construir un horizonte humano}

Ante las violencias, las indiferencias y las exclusiones propias de un tiempo de competitividad, crisis y transformaciones, la construcción de un horizonte humano se convierte en una necesidad imperante para los escenarios sociales y educativos. La escuela no puede cerrar los ojos ante esta realidad, ni dejar de comprender que, antes que conocimientos en abstracto, tiene la responsabilidad de formar en la humanización, más aún en tiempos como los actuales, en los que la amenaza de la "estética de la muerte" (Fajardo, 2005), la presencia de la "violencia transpolítica" (Mendoza, 2012) y los imperativos de lo hard y lo psi (Lipovetsky, 2006), se evidencian en los escenarios culturales cotidianos y en los espacios mediáticos.

Educar, entonces, implica comenzar a pensar, incluso desde la primera infancia, que lo humano no debe perderse de vista como estatuto necesario del saber, que es su fundamento y su esencia y que definitivamente la escuela es el espacio para generar alternativas ante las problemáticas de los tiempos del consumo. Los procesos de enseñanza-aprendizaje, implican, en este sentido, ser repensados desde la condición humana y darle cabida no sólo a los problemas de matemáticas, sino a aquellos que aquejan a los niños y niñas y les llevan al silencio y a la incomprensión. No se trata de volver al aula una clínica terapéutica, sino un escenario humano en el que el ser y el ser con otros están por encima de cualquier otro compromiso.

He ahí el desafío de la escuela y de nuestra sociedad en tiempos como los actuales. Se trata de consolidar las bases esenciales de lo humano, reivindicándole a través de su plena realización y su comprensión desde cuando se dan los primeros pasos y la inocencia orienta la mirada de un ser que sólo está completo en el momento en el que es capaz de abrazarse a sí mismo, a los otros y a la condición de pertenecer a una sola especie, un solo género y un único reto que jamás debe perderse de vista en medio de avances y desarrollo: " el de recuperar cuánto de humanidad hayamos perdido” (Sábato, 2002). 


\section{Referencias}

Amador, A. (2004). Vivir y trascender en familia: a través de los valores humanos. México: Trillas.

Baudrillard, J. (2009). La sociedad de consumo. Madrid: Siglo XXI.

Amador, A. (2007). Cultura y simulacro. Barcelona: Editorial Kairós.

Amador, A. (2006). El complot del arte: ilusión y desilusión estéticas. Buenos Aires, Madrid: Amorrortu Editores.

Baudrillard, J. y Morin, E. (2004). La violencia del mundo. Buenos Aires: Zorzal.

Bauman, Z. (2010). Modernidad Líquida. Buenos Aires: Fondo de cultura económica argentina.

Bauman, Z. (2007). Vida de consumo. México: Fondo de cultura económica.

Bauman, Z. (2005). Modernidad y ambivalencia. Barcelona: Editorial Anthropos

Bauman, Z. (2005). Los retos de la educación en la modernidad líquida. Barcelona: Gedisa.

Buenaventura, N. (1997). La maestra: por una pedagogía de los derechos humanos en la escuela colombiana. Barcelona: Piani.

Bruner, J. (1980). Realidad mental y mundos posibles. Barcelona: Gedisa.

Calvino, I. (2010). Seis propuestas para el próximo milenio. Madrid: Siruela.

Castells, M. (2009). Comunicación y poder. Madrid: Alianza.

Castro Pinzón, E. (2000). El Sujeto de la Educación. Bogotá: Universidad Nacional.

Fajardo, C. (2005). Estética y sensibilidades posmodernas. México: ITESO, Universidad Iberoamericana León.

Fajardo, C. (2010). Rostros del autoritarismo. Bogotá: Le monde diplomatique.
Habermas, J. (1987). Teoría de la acción comunicativa. Taurus: Madrid.

Koplow, L. (2005). Escuelas que curan. Buenos Aires: Troquel.

Lipovetsky, G. (2006). La era del vacío. Barcelona: Anagrama.

Lipovetsky, G. (2000). El imperio de lo efímero. La moda y su destino en las sociedades modernas. Barcelona: Editorial Anagrama.

Lipovetsky, G. (2010). La cultura mundo: respuesta a una sociedad desorientada. Barcelona: Anagrama.

Lipovetsky, G. (2006). Los tiempos hipermodernos. Barcelona: Anagrama.

Lipman, Matthew. (1997). Pensamiento complejo y educación. Madrid: Ediciones de la Torre.

Marzano, M. (2010). La muerte como espectáculo. Buenos Aires: Tusquets.

Medina Gallego, C. (2007). ¿Cómo se hace una clase? Didáctica de lo posible. Obtenido el 18 de enero de 2013, desde http://virtual.uptc.edu.co/revistas/index.php/psicopedagogia/article/view/381

Mendoza, M. (2012). Violencia transpolítica. Obtenido el 18 de enero de 2013, desde http://violenciatrasnpolitica.blogspot.com/

Morin, E. (1999). Siete saberes necesarios para la educación del futuro. Bogotá: Magisterio.

Piaget, J. (1975). Biología y conocimiento. México D.F.: Siglo XXI

Restrepo, M. (2005). Construcción de subjetividades y pedagogía en derechos humanos. Bogotá: Oficina en Colombia del Alto Comisionado de las Naciones Unidas para los Derechos Humanos.

Sábato, E. (2002). Antes del fin. Barcelona: Seix Barral.

Sábato, E. (2010). La resistencia. Barcelona: Seix Barral. 
Santos Guerra, M. (2010). La evaluación como aprendizaje. Buenos Aires: Bonum.

Saavedra, C. y Serrano, O. (2008). Derechos humanos: toda una cultura. Reflexiones en el aula de clase en torno a su pedagogía, docencia e investigación. Bogotá: Universidad Colegio Mayor de Cundinamarca.

Sibilia, P. (2005). El hombre postorgánico. Cuerpo, subjetividades y tecnologías digitales. Buenos Aires: Fondo de Cultura Económica.

Suarez Higuera, M. (2003). Familia y Valores. Modulo 1. Bogotá: Editorial Magisterio.

Tishman, S. (1997). Un aula para pensar: aprender y enseñar en una cultura de pensamiento. Buenos Aires: Aique.

Vigotsky, Lev. (1967). Pensamiento y Lenguaje. Buenos Aires: Lautaro. 